\title{
Study of Thermal Annealing Effect on the Properties of Silver Thin Films Prepared by DC Magnetron Sputtering
}

\author{
F. HAJAKBARI* AND M. EnSANDOUST \\ Department of Physics, Karaj Branch, Islamic Azad University, Karaj, Iran
}

\begin{abstract}
Silver nanoparticles have potential applications in fields of nanosicence and technology. In this work, polycrystalline silver $(\mathrm{Ag})$ thin films were deposited on quartz substrates by DC magnetron sputtering method at the same deposition conditions and then, the $\mathrm{Ag}$ films were annealed in oxygen atmosphere for 65 min at different annealing temperatures namely $300,400,500$ and $600^{\circ} \mathrm{C}$. The crystal structure of the films was evaluated by $\mathrm{X}$-ray diffraction. The atomic force microscopy and scanning electron microscopy were employed for surface morphological studies of the films. Normal-incidence transmittance over the wavelength range of 200-2500 $\mathrm{nm}$ was measured using a spectrophotometer. The results show that the crystallization of the films increases after annealing and that the Ag films without annealing have lowest roughness. Annealing temperature effectively influences the surface morphology of the films. Optical studies reveal that the as-deposited Ag film has metallic behavior with zero transmittance and after annealing, the transmittance increases due to the formation of silver oxide phases in the films.
\end{abstract}

DOI: 10.12693/APhysPolA.129.680

PACS/topics: 81.15.cd, 81.40.-z, 68.55.-a, 68.60.-p

\section{Introduction}

Silver and silver oxide nanoparticles have potential applications in fields of nanosicence and technology [1-14]. Silver thin films can achieve unique optical and electrical properties and can have better performance relative to other metal films in optical applications. Silver layers are ideal reflecting and conducting electrodes for thin film solar cells [14]. The silver-oxygen system contains several compounds, including $\mathrm{AgO}, \mathrm{Ag}_{2} \mathrm{O}, \mathrm{Ag}_{2} \mathrm{O}_{3}$ and $\mathrm{Ag}_{3} \mathrm{O}_{4}$ [1, 2]. The $\mathrm{AgO}$ phase is relatively stable at high oxygen pressures and at low temperatures [2]. Silver and silver oxide thin films had been prepared by several techniques including $\mathrm{RF}$ and $\mathrm{DC}$ sputtering $[6,9]$, thermal evaporation $[1,4,5]$, chemical synthesis and by pulsed laser deposition (PLD) $[2,10-12]$. In the present investigation, DC magnetron sputtering was employed to prepare Ag films and the effect of annealing on the structural, morphological and optical properties of $\mathrm{Ag}$ films at different temperatures were investigated.

\section{Materials and methods}

In the first step, $\mathrm{Ag}$ films were deposited on $1 \times 1 \mathrm{~cm}^{2}$ quartz substrates by DC magnetron sputtering at the same deposition conditions. Prior to deposition of the films the substrates were cleaned ultrasonically in acetone and ethanol for $15 \mathrm{~min}$. The sputtering target was of the metal silver with purity of $99.999 \%$. Prior to deposition, the deposition chamber was pumped to base pressure of $6.5 \times 10^{-5}$ mbar. After the introduction of the sputtering

\footnotetext{
* corresponding author; e-mail: fatemeh.hajakbari@kiau.ac.ir
}

gas (Ar 99.999\%) into the chamber the deposition pressure reached $5 \times 10^{-2}$ mbar. The deposition time for all films was $35 \mathrm{~s}$. The target to substrate distance was kept at $7 \mathrm{~cm}$ and the deposition was done at room temperature. The thickness of Ag films was $40 \mathrm{~nm}$. In the second step, the Ag films were annealed in oxygen atmosphere for 65 min at different temperatures namely 300, 400, 500 and $600{ }^{\circ} \mathrm{C}$. The crystal structure of the films was evaluated by X-ray diffraction (XRD) (PHILIPSX' Pert \& $\mathrm{PW} 1800)$ with $\mathrm{Cu} \mathrm{K}_{\alpha}$ radiation $(\lambda=1.5418 \AA)$. For surface morphological studies of the films the atomic force microscopy (AFM) (Manufactured by park Scientific Instruments) in contact mode and scanning electron microscopy (SEM) (ModelS-4160builtby Hitachiin Japan) were employed. Normal-incidence transmittance $(\mathrm{T})$ over the wavelength range $200-2500 \mathrm{~nm}$ was measured using a double beam spectrophotometer (CARY 500 Scan).

\section{Results and discussion}

The XRD spectra of the prepared films are shown in Figs. 1 and 2a-d. Figure 1 presents the XRD spectrum of the $\mathrm{Ag}$ films deposited on quartz substrate. The polycrystalline Ag films can be observed and the peaks namely the (111), (200), (220) and (311) visible in Fig. 1 are due to the cubic Ag phase. The similar results were observed by X. Sun et al. [7]. The (111) Ag peak intensity was larger than that of the other peaks because the (111) direction in $\mathrm{Ag}$ film has the lowest surface energy. The XRD spectra of the Ag films annealed at different temperatures are shown in Figs. 2a-d. For the annealed films, we can observe that the intensity of the $\mathrm{Ag}$ (111) peak enhances with the increase of the annealing temperature up to $500^{\circ} \mathrm{C}$ (Figs. 2a-c) and then decreases with the increase of annealing temperature to $600^{\circ} \mathrm{C}$ (Fig. 2d). In addition, the $\mathrm{Ag}_{2} \mathrm{O}_{3}$ (200) appears in XRD pattern of films annealed at temperatures 
in the range of $400-600^{\circ} \mathrm{C}$, Figs. $2 \mathrm{~b}-\mathrm{d}$. The high intensity and sharp peaks in XRD patterns confirm the highly oriented and polycrystalline nature of the Ag films prepared in this study.

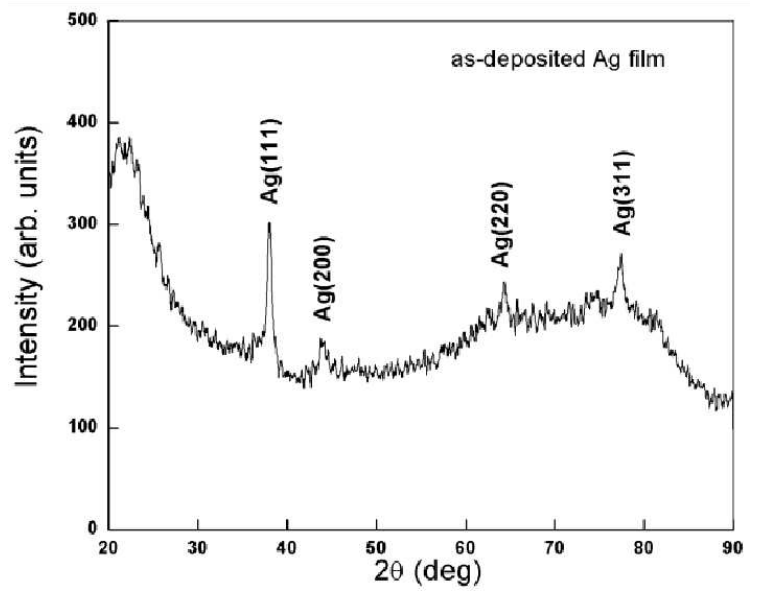

Fig. 1. The XRD pattern of as-deposited Ag film on quartz substrate.
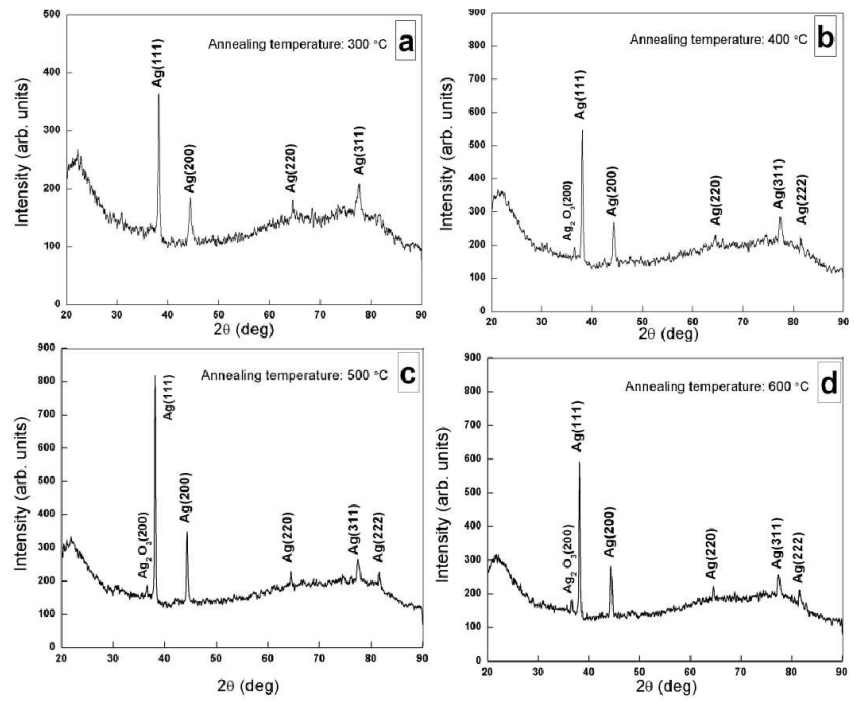

Fig. 2. XRD patterns of Ag films annealed at different temperatures (a) $300^{\circ} \mathrm{C}$, (b) $400{ }^{\circ} \mathrm{C}$, (c) $500^{\circ} \mathrm{C}$, (d) $600^{\circ} \mathrm{C}$

Surface morphology of the films was examined by AFM analysis. The scan area for all films was $2 \times 2 \mu \mathrm{m}$. Figures $3 \mathrm{a}$ and $\mathrm{b}$ show two and three dimensional AFM images of the as-deposited Ag films on quartz substrate. The small particles have grown on substrate surface and the pyramidal morphology can be seen. The average surface roughness of this film is $1.28 \mathrm{~nm}$. After annealing, the surface morphology of the films has completely changed. By increasing the annealing temperature from 300 to $600^{\circ} \mathrm{C}$ (Figs. 2a-d) the average roughness increased from $11.63 \mathrm{~nm}$ to $25.88 \mathrm{~nm}$. This behavior is due to the increase in annealing temperature that leads to an increase of the mobility of atoms. This increase of mobility causes the agglomeration of particles and creation of larger particles which in turn leads to an increase of the films roughness.
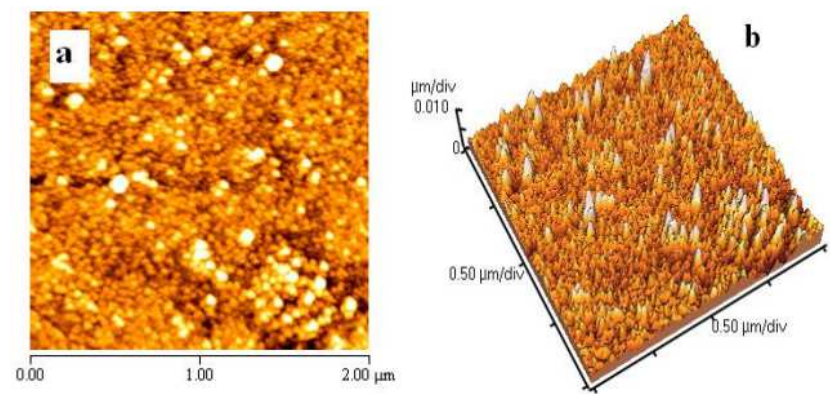

Fig. 3. (a) 2D and (b) 3D AFM images of Ag films deposited on the quartz substrate.
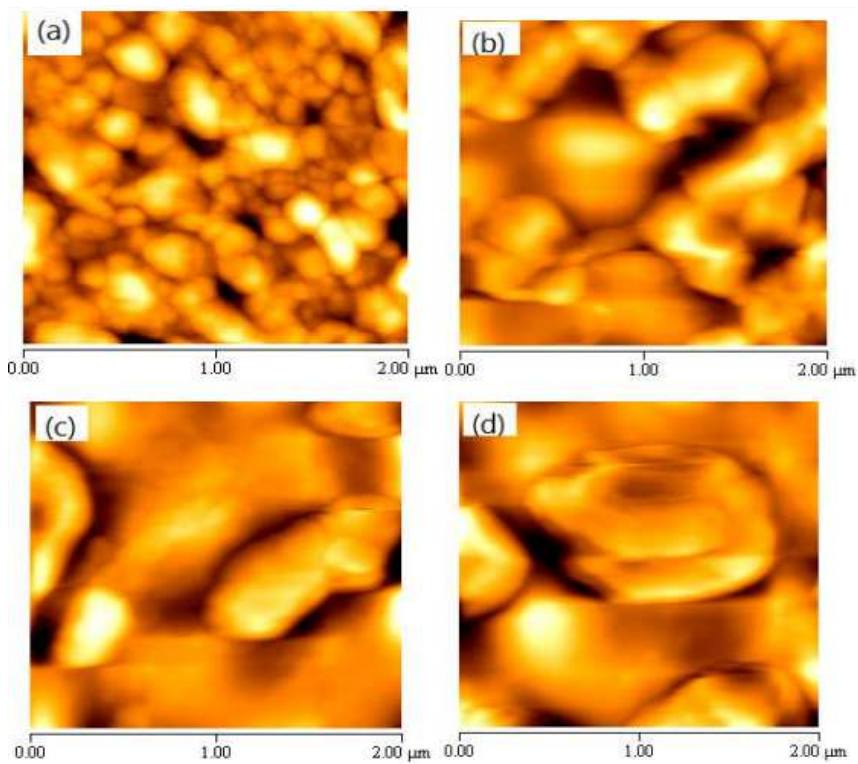

Fig. 4. 2D AFM images of Ag films deposited on quartz substrates and annealed at different temperatures (a) $300{ }^{\circ} \mathrm{C}$, (b) $400^{\circ} \mathrm{C}$, (c) $500^{\circ} \mathrm{C}$ and (d) $600^{\circ} \mathrm{C}$.

Figures 5a-e show SEM images of Ag films deposited on quartz substrate and annealed at different annealing temperatures. The surface of $\mathrm{Ag}$ film without annealing was relatively smooth Fig. 5a. A few holes have appeared after annealing at $300^{\circ} \mathrm{C}$, Fig. 5b. When the film was annealed at $400^{\circ} \mathrm{C}$, Fig. $5 \mathrm{c}$, particles have started to separate and the gaps between particles have been enlarged and grain structure with diameters of around 56-79 $\mathrm{nm}$ has appeared after such treatment. Moreover, when annealing temperature was increased to $500^{\circ} \mathrm{C}$ and $600^{\circ} \mathrm{C}$ the particles shape has approached the globular shape and the gap between particles has expanded further (Figs. 5d and e). Similar morphology was obtained in $[14,15]$. The results show that annealing temperature significantly influenced the size and shape of silver particles. 

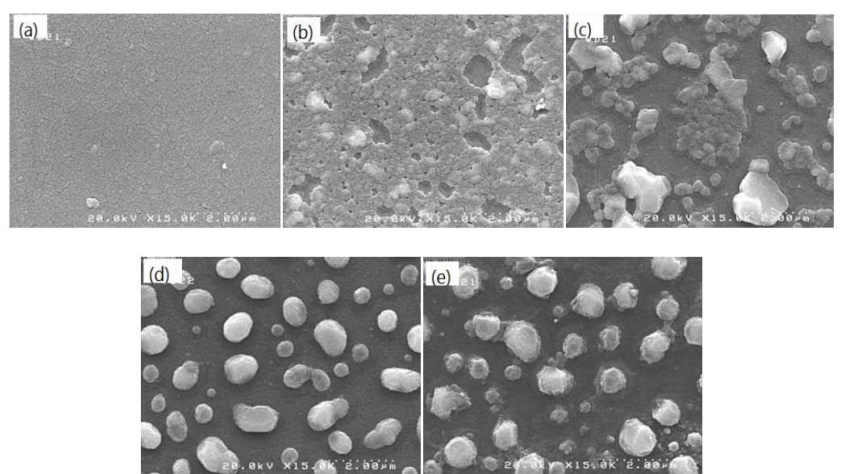

Fig. 5. SEM micrographs of Ag films on quartz substrates at different annealing temperatures (a) without annealing, (b) $300{ }^{\circ} \mathrm{C}$, (c) $400{ }^{\circ} \mathrm{C}$, (d) $500^{\circ} \mathrm{C}$ and (e) $600{ }^{\circ} \mathrm{C}$

The transmittance spectra of the Ag films prepared at different annealing temperatures, in the wavelengths range of $200-2500 \mathrm{~nm}$ are shown in Fig. 6. The asdeposited films have a metallic behavior with zero transmittance. After annealing of the films the transmittance increases due to formation of silver oxide films. Also, the transmittance spectra show a resonant increase in transmittance at wavelength of $320 \mathrm{~nm}$ for all films, which can be due to the localized surface Plasmons [1].

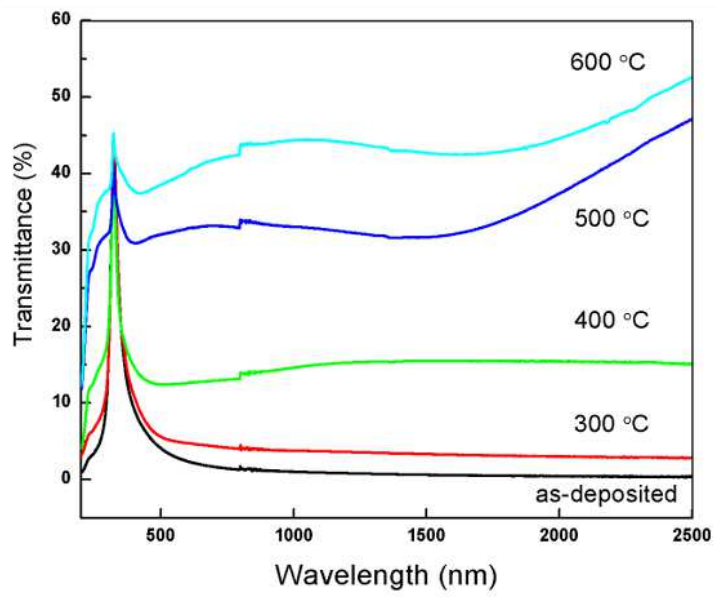

Fig. 6. The transmittance spectra of as-deposited Ag films, and the films annealed at different temperatures on quartz substrates.

\section{Conclusions}

The effect of annealing temperature on crystal structure, surface morphology and optical properties of silver thin films was investigated by XRD, AFM, SEM and spectrophotometry. The XRD results have shown that the nanocrystalline Ag films with preferred orientation along (111) direction can be observed before annealing and by increasing of annealing temperature up to $400^{\circ} \mathrm{C}$ no significant changes occur in the film structure. The silver oxide phase and improvement of crystallinity was observed after annealing at temperatures of $500{ }^{\circ} \mathrm{C}$ and $600{ }^{\circ} \mathrm{C}$. It was found that the annealing temperature significantly influenced the size and shape of the silver particles. The best crystallinity and surface morphology was observed at annealing temperature of $500{ }^{\circ} \mathrm{C}$ and the good transparency was obtained at annealing temperature of $600^{\circ} \mathrm{C}$.

\section{References}

[1] M.F. Al-Kuhaili, J. Phys. D: Appl. Phys. 40, 2847 (2007).

[2] N.R.Ch. Raju, K.J. Kumar, A. Subrahmanyam, J. Phys. D: Appl. Phys. 42, 135411 (2009).

[3] F.X. Bock, T.M. Christensen, S.B. Rivers, L.D. Doucette, R.J. Lad, Thin Solid Films 468, 57 (2004).

[4] J. Lv, F. Lai, L. Lin, Y. Lin, Z. Huang, R. Chen, Appl. Surf. Sci. 253, 7036 (2007).

[5] H.C. Kim, T.L. Alford, D.R. Allee, J. Appl. Phys. Lett. 81, 4287 (2002).

[6] X. Sun, R. Hong, H. Hou, Z. Fan, J. Shao, Thin Solid Films 515, 6962 (2007).

[7] A. Dahshan, K.A. Aly, Acta Mater. 56, 4869 (2008).

[8] K. Kusaka, D. Taniguchi, T. Hanabusa, K. Tominaga, Vacuum 59, 806 (2000).

[9] Y.H. Yoon, S.-M. Yi, J.-R. Yimi, J.-H. Lee, G. Rozgonyi, Y.-C. Joo, Microelectron. Eng. 87, 2230 (2010).

[10] R. Deng, J. Li, H.K. Kang, H.J. Zhang, C.C. Wong, Thin Solid Films 519, 5183 (2011).

[11] T.L. Alford, L. Chen, K.S. Gadre, Thin Solid Films 429, 248 (2003).

[12] J. Tominaga, J. Phys.: Condens. Matter 15, R1101 (2003).

[13] O. Akhavan, R. Azimirad, A.Z. Moshfegh, J. Phys. D: Appl. Phys. 41, 195305 (2008).

[14] R. Santbergen, T.L. Temple, R. Liang, A.H.M. Smets, R.A.C.M.M. Van Swaaij, M. Zeman, J. Opt. 14, 024010 (2012).

[15] J.H. Hsieh, Ch. Li, Y.Y. Wu, S.C. Jang, Curr. Appl. Phys. 11, S328 (2011). 